\title{
Planning rice cultivation in a large plot agricultural system
}

\author{
Montri Singhavara ${ }^{\mathrm{a}}$, Kamoltip Panyasit ${ }^{\mathrm{b}}$ and Sakkarin Nonthapot ${ }^{\mathrm{c}^{*}}$
}

${ }^{a}$ Department of Economics, Faculty of Economics, Maejo University, Chiang Mai, Thailand 50290

${ }^{b}$ Department of Business Administration, Faculty of Interdisciplinary Studies, Khon Kaen University, Nong Khai, Thailand 43000 ${ }^{c}$ Department of Social Sciences, Faculty of Interdisciplinary Studies, Khon Kaen University, Nong Khai, Thailand 43000

\section{H R O N I C L E}

Article history:

Received September 1, 2021

Received in revised format:

September 15,2021

Accepted October 312021

Available online

October 31, 2021

Keywords:

Large agricultural land plot

guidelines

Rice

Multiple-criteria decision-making

Multi-choice goal programming

Trade-offs

\section{A B S T R A C T}

This research aimed to study the approach of the community toward the decision to grow rice and economic crops, including appropriate resource allocation for use on a farm under a large plot agricultural system. The study areas were in Phan district, Chiang Rai province, Thailand, and the data were collected from a sampling of 400 field agriculturalists. The method used was to develop a mathematical model for growing crops with multi-objectives and in multi-periods, together with an agriculturist representative and experts in multiple-criteria decision-making (MCDM). This was to prioritize the importance of alternative crops and find the appropriate allocation of the resources to achieve the targeted goal. The results showed that agriculturists prioritized most toward the criteria for growing Japanese rice with a weight of $0.179 \mathrm{Kg}$, followed by transplanted rice, transplanted glutinous rice, garlic, sown paddy rice, and sown glutinous paddy rice, respectively. The study's results also showed that the price fluctuation of the crop products resulted in more use of land and labor in order to increase the production to compensate for the low price, and this also resulted in the higher opportunity cost of growing transplanted rice. Therefore, growing transplanted rice during in season planting was considered the most effective way, while during the off season, either garlic or Japanese rice could be grown. A collective pattern for planning for using resources together in large plot agricultural areas, together with a clear marketing target would bring about effective use of the resources and reduce the risk in revenue from the fluctuation in prices and uncertainty of yields from drought. Moreover, technology development to solve the problem of the lack of labor would be deemed an important approach toward the enhancement of the competitiveness of agriculturists in the future as well.

\section{Introduction}

With regard to the structural problem of Thailand's rice production system and the importance of rice cultivators in the Upper Northern region, the Ministry of Agriculture and Cooperatives planned and initiated the policy to solve the rice problem for all agriculturalists for the long run. The active policy in the fiscal year 2016 included the promotion of large agricultural plots. This implementation with the rice cultivators aimed to encourage them to coordinate together for the large agricultural plots. The goal of this policy was to reduce the costs in order to enhance the competitive advantage of the rice cultivators (economy of scale). They prioritized utilizing production factors (fertilizers, pesticides, and grains), labor and agricultural machines, soil improvement, and administration. The group appointed a plot manager (the representative from the governmental unit) to manage and coordinate the group members to follow the guidelines. The criteria of the agricultural group were the agricultural plots must be located nearby to each other, and the size of the 50 members' plots was not over 1,000 rai. The responsibility

* Corresponding author.

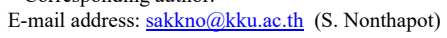

(C) 2022 by the authors; licensee Growing Science, Canada.

doi: $10.5267 /$ j.dsl.2021.10.003 
of the agricultural groups according to the large agricultural plot guidelines consisted of 1) the gathering and process management of the group to operate the large agricultural plot, 2) cooperative production and marketing with the analytical process and target setting (return, production quantity, and price), 3) managing the implementation plan and selecting appropriate technology for the production and marketing process, and 4) deciding the use of the production factors by collaborating together for the purchase or procurement. In accordance with the large agricultural plot guidelines that had been operated in the fiscal year 2016, the provinces in the Upper Northern region that contained the potential surface included 1) Chiang Rai comprising Wiang Chai, Phan, and Khun Tan districts with 1,000 rai each and Chiang Khong district with 2,000 rai, and 2) Phayao with 1,400 rai in Mueang district. Consequently, to compare the appropriate proportion and area for rice cultivation, there were many major opportunities to increase the group number or the size of the large agricultural plot. However, the group of agriculturalists to plan the product (the use of the production factors), the marketing (selling volume), and the goal was deprived of a crystal clear pathway, and the operation was unable to examine the quantity. Furthermore, it was unable to evaluate the economic effects of the environmental uncertainty (e.g., water volume or climate), and economic uncertainty (e.g., price or cost). As a result, this study proposed to find a pathway for the decision-making to appropriately use factors with multiple-criteria decision-making (MCDM) and participation of the agriculturalists to prioritize the alternatives according to the criteria or the constraints in the community's resources and technology. As aforementioned, this research aimed to 1. realize the decision of the agriculturalists in prioritizing rice cultivation and economic crops to achieve the goal set by the community, and 2. develop the mathematical model and decision-making guidelines toward the use of the production factors for rice cultivation in the large agricultural plot system with efficiency. Additionally, the results of the study would support the building of the original model of the large agricultural plot guidelines and the development of precision agriculture or smart farmers that would evaluate the competitiveness of Thai agriculturalists in the future.

\section{Literature Review}

MCDM and multiple-objective decision-making (MODM) have been widely utilized to find the allocation management of the production factors and resources in order to make a decision and to plan agriculture and alternative energy. Jablonski et al. (2010) surveyed the prediction and use of bioenergy production for the energy sustainability of the United Kingdom by building the BIOSYS-MAKAL model. Their study demonstrated the complexity of the route of using bioenergy in several forms, especially bioheat and biofuel for the great potential of transportation. The project's success depended on the readiness of the resources and marketing conditions. Callesen et al. (2010) applied simple linear programming to find the production resource allocation pathway under the demand of energy use in Denmark. The study found the lowest cost of energy production under the limited condition of the system; in other words, the site of the cultivation. The reserved site for conservation contained the nitrogen volume that followed the cultivation standard (co-cultivation of energy plants) and the limited quantity of food for humans and animals since bioenergy was related to the cultivation system and plant sales. Therefore, most research studies examined the impact forecast of the supply chain system for bioenergy production toward the exploitation of the resources, and for suggesting the appropriate technology by applying multi-criteria optimization and genetic algorithm optimization (Ayoub et al., 2009). In addition, the application of the goal programming model to set the goal was regarded as a major pathway of the decision-maker, as it assisted in producing the right policy and plan. Recently, some studies have broadly applied this pathway similar to Cristobal (2012), who used the goal programming model to realize the effect of the products and employment of the economic sector due to the decrease in pollution and energy demand. Moreover, with the uncertainty or ambiguity of the agricultural data, some types of data required knowledge or experiences of the decision-maker; for instance, agricultural products, water volume, and goal. In consequence, in applying fuzzy goal programming (FGP) to build the resource usage model for in season crop cultivation with the concern of social demands (Biswas et al., 2005), the use of the FGP model and the lexicographic goal programming (LGP) model evaluated the employment opportunities in the rural area. Furthermore, the processing results by the MODM demonstrated trade-offs that reflected the scarcity; such as, land, water, labor, and energy. Trade-off, therefore, was defined as to lose something or to increase something. Something that we did not select would become an opportunity cost, which would be regarded as the major economic principle or the pathway of selection or decision-making in many cases. As a result, it could be said that the opportunity cost was the best alternative value from other unselected options. Thus, many research studies prioritized this principle. For example, Beck et al. (2008) made a goal of an energy plan by using multi-objective optimization and represented a trade-off between the economy, environment, and society.

\section{Methodology}

The study on the decision-making guidelines toward the appropriate use of the production factors under the concept of the large agricultural plot system applied MCDM that contained two main parts as follows: 1) The decision-making by the fuzzy analysis hierarchical process (FAHP) to receive the priority weight of the agriculturalists toward the alternatives in crop cultivation and sales; 2) the development of multi-goal, multi-choice, and multi-period linear programming with extended goal programming. These models were examined to calculate the suitable values in using land, labor, and water in order to achieve the main goal that was to receive the highest return from rice cultivation and alternative economic crops in season and off season under the resource, land, water, and labor conditions. 


\subsection{Population and Samples}

In order to encourage land use for implementation, the author selected the land with the potential surface, and people in the community were ready and agreed to cooperate in giving information. According to the field survey in Phan district, Chiang Rai province, which followed the aforementioned criteria, the cultivated plants during August-December were transplanted rice (objective $1 \mathrm{C}$ ), sown paddy rice (objective $2 \mathrm{~V}$ ), glutinous transplanted rice (objective $3 \mathrm{~B}$ ), and sown glutinous paddy rice (objective $4 \mathrm{E}$ ). During the drought, or December-April, for the plants that could tolerate the conditions and gave a return instead of in season rice, with concern for the technological feasibility for the cultivation by the agriculturalists in the study site, the model simulated two plants, which were Japanese rice (objective $5 \mathrm{~J}$ ) and garlic (objective $6 \mathrm{G}$ ). The study samples included agriculturalists who cultivated the mentioned six plants in the study areas, and they had the readiness to form a group to follow the large agricultural plot pathway. The initial total number was 67 households; moreover, there were more than 300 agriculturalist households who could follow in the future. The total study area size was 4,358 rai.

\subsection{Data Analysis}

The study pathways consisted of two major steps as follows:

3.2.1 Fuzzy analysis hierarchical process $(F A H P)$ is a process of MCDM used to solve complex problems by selecting the best alternative. This process was developed by Saaty in 1980 by combining the fuzzy set theory in the fuzzy analysis, which was unclear and difficult to ascertain. This performed hierarchical prioritization by comparing the pairs and using fuzzy data instead of scoring with a number (Ceilik et al., 2009). Due to the FAHP, the result would show the weight value.

\subsubsection{Extended goal, multi-choice and multi-period linear programming}

The participatory meeting resulted in the realization of the alternatives or objectives that the agriculturalists needed to achieve. They were the highest return from cultivating six plants. The cultivation was divided into four parts that were implanting, caring, harvesting, and selling products. For the continuity of the planning and representing the dynamics of cultivation, the duration was scheduled for three years (36 months). The model could be displayed as follows:

The equation of the objective showed the net return from the cultivation and sales of six alternative plants (following the process from the FAHP). The activities in the cultivation process included selling (income), growing cost (tending and harvesting), labor cost, and water cost.

$$
\begin{aligned}
Z_{i}^{F}= & \sum_{t=1}^{36} \sum_{s=1}^{2}\left(\widetilde{P_{i t}} \cdot \widetilde{y_{i t}}\right) \cdot \operatorname{Area}_{i s t(j=4)}-\sum_{t=1}^{36} \sum_{s=1}^{2} \sum_{j=1}^{3}\left(C l_{i j} \text { Area }_{i s t j}\right)-\sum_{t=1}^{36} \sum_{s=1}^{2} \sum_{j=1}^{4}\left(C H_{t} \cdot H i L a_{i s t j}\right) \\
& -\sum_{t=1}^{36} \sum_{s=1}^{2} \sum_{j=1}^{4}\left(C W_{t} \cdot H i W_{i s t j}\right) \quad \forall i \quad i=1, \ldots, 6
\end{aligned}
$$

From Eq (1), the price range $\left(\widetilde{P}_{i t}\right)$, yield $\left(\widetilde{Y_{i t}}\right)$ and cost $\left(C_{i j t}\right)$, regarding the field study of the sample agriculturalists during the cultivation in 2016-2019, resulted in the range of the sales price and the output quantity of the agriculturalists (minimummaximum). This was because each agriculturalist had a different production capacity and error of receiving information; therefore, the data became uncertain or fuzzy. The production cost $\left(C_{i j t}\right)$ was sorted by the activity (implant, care, and harvest) that the parameter values are shown in Table 1. The labor cost rate was THB 300/day (THB 37.5/working hour), and because the study field was located in an irrigation area, the water cost was very low. Therefore, the water cost was set at THB $1 / \mathrm{m}^{3}$ (Table 1).

Table 1

\begin{tabular}{|c|c|c|c|c|c|c|c|c|}
\hline \multirow[b]{2}{*}{ Plant } & \multicolumn{3}{|c|}{ Price Range (Thai Baht/Kg.) $\left(\tilde{P}_{i t}\right)$} & \multicolumn{2}{|c|}{ Yield (Kg. /Rai) $\left.\widetilde{(Y}_{i}\right)$} & \multicolumn{3}{|c|}{ Cost (Thai Baht/Rai) $\left(C_{i j t}\right)$} \\
\hline & $\begin{array}{c}\text { Year } \\
2015 / 16\end{array}$ & Year 2016/17 & Year 2017/18 & $\begin{array}{c}\text { Soil Highly } \\
\text { Suitable (S1) }\end{array}$ & $\begin{array}{c}\text { Soil } \\
\text { Moderately } \\
\text { Suitable (S2) }\end{array}$ & Implant & Care & Harvest \\
\hline $\mathrm{C}$ & $14.31-16.07$ & $14.31-16.07$ & $11.64-14.25$ & $902-1,066$ & $922-1,127$ & 2,852 & 938 & 1,117 \\
\hline V & $14.313-16.07$ & $14.313-16.07$ & $11.64-14.25$ & 786-825 & $802-871$ & 1,170 & 2,624 & 945 \\
\hline B & $12.42-13.36$ & $12.42-13.36$ & $9.92-12.69$ & $1,017-1,202$ & $1,017-1,202$ & 1,975 & 1,040 & 1,404 \\
\hline $\mathrm{E}$ & $12.42-13.36$ & $12.42-13.36$ & $9.92-12.69$ & $908-926$ & 927-981 & 1,936 & 1,277 & 1,996 \\
\hline $\mathrm{J}$ & $9.5-12.30$ & $9.5-12.30$ & $9.50-12.30$ & $810-830$ & $806-818$ & 1,800 & 3,173 & 1,100 \\
\hline $\mathrm{G}$ & $10.0-25.0$ & $10.0-25.0$ & $10.0-25.0$ & $945-1,035$ & $956-1,068$ & 8,252 & 5,033 & 1,851 \\
\hline
\end{tabular}

Sales price, quantity of the output, and production costs.

Source: Field survey and data from the Department of Internal Trade, Chiang Rai province, 2019. 
The equations of constraints were as follows:

(1) The constraint of the water requirement during drought and the rainy season.

$$
\begin{aligned}
& \operatorname{Tr} W_{t(w=1)}-\operatorname{HiW}_{t(w=2)} \leq \widetilde{\operatorname{Wat}}_{t(w=1)} \quad \exists t \\
& \operatorname{Tr} W_{t(w=1)}-\operatorname{Tr} W_{(t-1)(w=1)} \leq \operatorname{HiW}_{t(w=2)} \quad \exists t \\
& \sum_{i=1}^{4} \sum_{s=1}^{2} \sum_{j=1}^{3} \widetilde{C W U}_{s t j} \text { Area }_{i s t j}+\operatorname{Tr} W_{t(w=1)}-\operatorname{Tr} W_{(t-1)(w=1)} \leq \widetilde{\operatorname{Wat}}_{t(w=3)}+H i W_{t(w=4)} \quad \exists t
\end{aligned}
$$

(2) The constraint of groundwater during drought and the rainy season.

$$
\begin{aligned}
& \sum_{t=1}^{T} H i W_{t(w=2)} \leq \widetilde{W Q R}_{w=2} \quad \exists t \\
& \sum_{t=6}^{T} H i W_{t(w=4)} \leq \widetilde{W Q R}_{w=4} \quad \exists t
\end{aligned}
$$

where; Irrigation water $\left(\widehat{W a t Q}_{t w}\right)$ groundwater $(\widetilde{W Q R})$ and water requirement $\left(\widetilde{C W U}_{i j}\right)$

The sample area has natural water resources, which are the Khao Ton River, brooks, and a natural swamp, including manmade water resources, i.e., 26 village water systems, 98 groundwater wells, 10 water reservoirs, 42 rainwater reservoirs, 69 weirs, five water pools, and 624 digging wells. According to the forecast by calculating the water volume, this could indicate the water volume from the irrigation system, and the value was approximately 3,996,659.2 -19,983,296 $\mathrm{m}^{3} /$ year. The water volume from the groundwater evaluated by the irrigation officers of Chiang Rai was approximately 121,816-1,763,600

\begin{tabular}{|c|c|c|c|c|}
\hline \multirow{2}{*}{ Plant } & \multicolumn{3}{|c|}{ Labor Requirement (Hour/Rai) $\left(L Q_{i j}\right)$} & \multirow{2}{*}{$\begin{array}{c}\text { Water Requirement } \\
\left(\text { Cubic Meters /Rai) }\left(\widehat{C W U}_{i j}\right)\right.\end{array}$} \\
\hline & Implant & Care & Harvest & \\
\hline Transplanted rice $(\mathrm{C})$ & 42.32 & 3.95 & 11.24 & $159.75-255.5$ \\
\hline Sown paddy rice $(\mathrm{V})$ & 5.63 & 4.77 & 15.50 & $159.75-255.5$ \\
\hline Transplanted glutinous rice (B) & 19.13 & 4.45 & 22.0 & $177.50-284.25$ \\
\hline Sown glutinous paddy rice $(\mathrm{E})$ & 10.76 & 3.84 & 39.02 & $177.50-284.25$ \\
\hline Japanese rice $(\mathrm{J})$ & 4.00 & 15.33 & 11.00 & $137.50-237.5$ \\
\hline Garlic (G) & 18.00 & 4.80 & 20.53 & $120.00-133.75$ \\
\hline
\end{tabular}
$\mathrm{m}^{3} /$ year. However, the water requirement $\left(\widetilde{C W}_{i j}\right)$ contained uncertainty; therefore, the result showed the data range (Department of Irrigation, 2014) (Table 2). This led to constraints (3) and (4).

Table 2

Labor and water requirement for crop cultivation.

Source: From the field survey and calculated.

(3) Constraint of the appropriate area toward the crop cultivation in the study field.

$$
\sum_{i=1}^{4} \text { Area }_{i s t j} \leq \text { Aland }_{s} \quad \forall t \quad \forall s
$$

(4) Using the harvesting area and caring area not over the implanting area.

$$
\begin{array}{lllll}
\operatorname{Area}_{i s(t+1)(j=2)} \leq \operatorname{Area}_{i s t j(j=1)} & \forall t & \forall i & \forall s \\
\operatorname{Area}_{i s(t+1)(j=3)} \leq \operatorname{Area}_{i s t j(j=2)} & \forall t & \forall i & \forall s
\end{array}
$$

In the appropriate area for cultivation $\left(\right.$ Aland $\left._{v}\right)$, from the Rice Department's information, there were 67 farmers who practiced the large agricultural plot. They possessed the cultivation area totaling 858 rai, which could be divided into 595 rai of the most appropriate rice cultivation area (S1) and 263 rai of the moderately appropriate rice cultivation area (S2). On the other hand, from the information of the Department of Land Development, Phan district still had the most appropriate area with more than 3,500 rai, and competent agriculturists to practice the large agricultural plot (Department of Land Development, 2007). In consequence, the study areas contained 4,385 rai. 
5) Constraint of household labor and employed labor for implanting, caring, and harvesting. The use of labor in crop cultivation was $i$ not over household labor and employed labor (Household worker capacity $\left(A L_{t}\right)$, local employed worker

$\left(\widehat{A H i L}_{t}\right)$, and labor rate for crop cultivation $\left.\left(L Q_{i j}\right)\right)$.

$$
\sum_{s=1}^{2} L Q_{i j} \text { Area }_{i s t j}-H i L_{i t} \leq A L_{t} \quad \forall j \quad \forall i \quad \exists t
$$

Maximum employed labor $i$ at a time $t$.

$$
H_{i L} \leq \widetilde{A H i L}_{t} \quad \forall i, \forall t
$$

As the average number of household members of the agriculturalists were three persons and the employed nearby labor was approximately 800-3,000 persons (Provincial Labor Office of Chiang Rai, 2013), in this study, one worker worked eight hours/day (eight working hours) and there were 25 working days/month; therefore, the number of working hours were calculated for 600 household workers and employed workers to be 160,000-600,000 working hours/month.

From hypotheses (1)-(7), the setting was as follows (sets):

$i=$ a type of crop $i \in I \quad I=1$ transplanted rice (C), $I=2$ sown paddy rice (V), $I=3$ transplanted glutinous rice (B),

$I=4$ is sown glutinous paddy rice $(\mathrm{E}), I=5$ is Japanese rice $(\mathrm{J})$, and $I=6$ is garlic $(\mathrm{G})$.

$S=$ Type of appropriate area $S \in S \quad S=1$ Primary appropriate area.

$t=$ Time of agricultural activities $t \in T$ Month 1-36.

$j=$ Crop cultivation activity $j \in J \quad J=1$ Implant, $J=2$ Care, $J=3$ Harvest, and $J=4$ Sales.

$w=$ Water Resource $w \in W \quad W=1$ Irrigation water, and $W=2$ Groundwater.

Decision Variables

Area $_{i t j} \quad$ Land use for cultivation $i$ cultivating activity $j$ time $t$ appropriate area $S$ (unit: rai).

$H i L a_{i t j}$ Employed labor requirement (unit: working hour).

$H i W_{i t j}$ Groundwater volume in drought and rainy season at a time $t$ (unit: $\mathrm{m}^{3}$ ).

$\operatorname{Tr} W_{t w}$ Remaining irrigation water volume at $t$ a time (unit: $\mathrm{m}^{3}$ ).

$\operatorname{Tr} W_{(t-1) w}$ Irrigation water transferred from time $t$ (unit: $\left.\mathrm{m}^{3}\right)$.

$H i L_{i t}$ Quantity of labor at a time $t$ (unit: working hour).

To study the fuzzy effect of the economic factors (product price and labor quantity) and environmental factors (water volume and output) toward the returns and resource allocation, this study depended on the fuzzy-min membership function by using the parameter with ambiguity. Here, $\alpha$ was the control parameter. In other words, when $\alpha$ increased near 1 , it demonstrated pessimism, but the result probably became real (e.g., low product price, low labor quantity, drought, and low output). When $\alpha$ increased near 0 , this inferred optimism, but the result was difficult to be real (e.g., higher product price, higher labor quantity, full water volume, and good output).

\subsubsection{Extended goal programming and multi-choice goal programming (MCGP)}

The result of the multi-period model could provide many resource allocation values with efficiency in accordance with the Pareto optimality. However, this might cause an imbalance in the answer. In other words, only plants with return effectiveness were selected because of the right result following the selection criteria. The extended GP (EGP) would result in the balanced allocation of resources between the efficiency philosophy and equity philosophy based on the goal achievement; moreover, the weight $\left(w_{i}\right)$ for the objective equation $i$ represented the participation of the community according to the FAHP. In addition, because the net return for every objective equation was set over one value, the MCGP was applied to achieve the goal of the net return with efficiency. This could demonstrate the use of the EGP model with the MCGP mode as follows:

Achievement function $a=(1-\lambda) D+\lambda \sum_{i=1}^{q}\left(\frac{w_{i} n_{i}}{k_{i}}+\frac{w_{i} p_{i}}{k_{i}}\right)$ subject to 


$$
\begin{aligned}
& f_{i}(x)+n_{i}-p_{i}=\sum_{j=1}^{m} g_{i j} S_{i j}(B) \quad i=1, \ldots, Q \\
& \frac{w_{i} n_{i}}{k_{i}}+\frac{w_{i} p_{i}}{k_{i}} \leq D \quad i=1, \ldots, Q \\
& S_{i j}(B) \in R_{i}(x) \quad i=1, \ldots, Q \\
& x \in F(F \text { is a feasible set }) \\
& n_{i}, p_{i} \geq 0 \quad \lambda \in[0,1] \quad i=1, \ldots, Q
\end{aligned}
$$

where $\lambda$ was the control parameter; therefore, $\lambda=0$. The author obtained the achievement function with the maximum equity but if $\lambda=1$, the achievement function with maximum efficiency would be obtained. When $\lambda$ exists in the range ( 0 , 1 ), the answer is between the Chebyshev goal programming (CGP) ( $\lambda=0$ or min-max goal programming) and weighted goal programming (WGP) $(\lambda=1)$. Simultaneously, $S_{i j}(B)$ demonstrates the function of the number 0 and 1 , and $R_{i}(x)$ represents the limited function of the resources.

\section{Results}

The organization of a participatory meeting between the representatives of the stakeholders in Phan district, Chiang Rai province was attended by the agriculturalist group that cultivated six crops, and representatives from the state sector (subdistrict agriculture, local administration, and academicians from educational institutes). This meeting aimed to specify the weight by using the FAHP to receive the hierarchical diagram and weight of the decision-making (Fig. 1). It demonstrated that the agriculturalists had the goal to produce rice for a sustainable return under the scope of the large agricultural plot guidelines, which consisted of six alternatives that were transplanted rice $(\mathrm{C})$, sown paddy rice $(\mathrm{V})$, transplanted glutinous rice (B), and sown glutinous rice (E), and economic crops that were Japanese rice (J) and garlic $(\mathrm{G})$. The weights were slightly different, but this showed that the agriculturalists gave priority to Japanese rice cultivation the most, as its weight was 0.179 kilograms (Kg.). The lesser values were transplanted rice, transplanted glutinous rice, garlic, sown paddy rice, and sown glutinous rice, as their weights were $0.171,0.169,0.161,0.155$, and $0.153 \mathrm{Kg}$., respectively. The reasons were they paid attention to the economic and social factors (ES) for 0.74, which was more than 0.26 of the environmental factor (ENV). The agriculturalists agreed that the sub-criteria took the main role toward their decision-making, and the three highest prioritized sub-criteria were price $(\mathrm{P})$ or 0.28 , support from the government $(\mathrm{G})$ or 0.17 , and cost $(\mathrm{C})$ or 0.16 . This was because the product sales were high that affected the financial flexibility. The agriculturalists could spend their daily life with ease and were able to pay off their debts. The support from the governmental sector in the form of a price guarantee or production aids were regarded as the supportive factor that reduced their return risk. Furthermore, production cost management greatly enhanced their competitiveness. The weight of the six alternatives could be processed as aforementioned, and the results would be weighted with the objective equations in the application of the EGP and MCGP models.

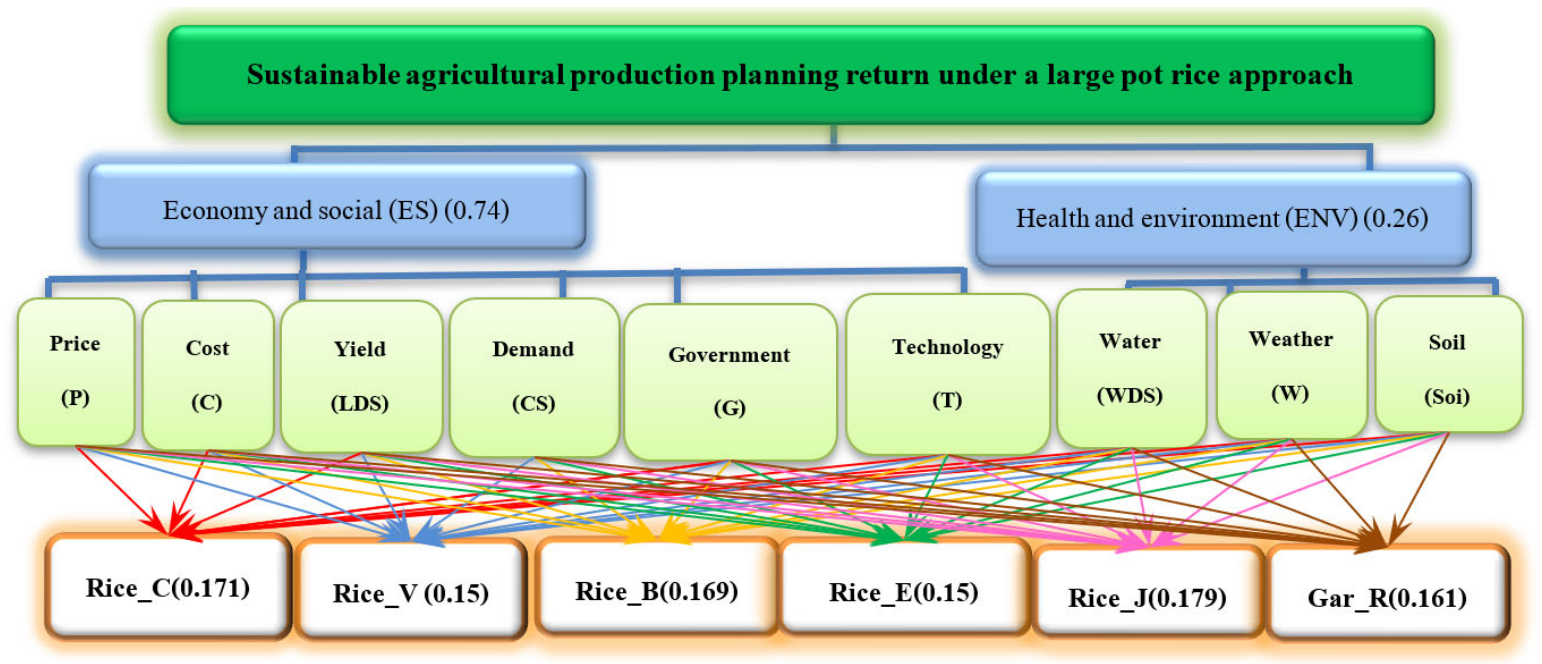

Fig. 1. Hierarchical analysis to sustainable agricultural production planning return

The achievement of the agriculturalists' goal by obtaining the return and appropriate resource allocation pathway 
With regard to the participatory meeting of the agriculturalist representatives to share the community's economic data from the governmental unit, this resulted in the receiving of the data range of a three-year return from every alternative as follows: transplanted rice (C) amounting to THB 0.25-60 million, sown paddy rice (V) amounting to THB 0.45-50 million, transplanted glutinous rice (B) amounting to THB 0.1-65 million, sown glutinous rice (E) amounting to THB 0.25-45.5 million, Japanese rice $(\mathrm{J})$ amounting to THB 0.2-30 million, and garlic $(\mathrm{G})$ amounting to THB 0.3-50 million. The result of the EGP and MCGP with the model of the multi-period cultivation in the large agricultural plot system was as follows:

Return of the agriculturalists: Firstly, $\lambda$ (equity and efficiency levels) was selected (Equation 8) that obtained the maximum net return at $\alpha$ (price uncertainty $\left(\tilde{P}_{i t}\right)$ and yields $\left(\tilde{Y}_{i t}\right)$ ); the result was $\lambda=0.15$ and $\alpha=0.15-0.25$ (Figure 2 red dotted line). This figure represented the net household return of the six alternatives amounting to THB 677,846/three years, and the cultivation could be planned with two alternatives as follows: 1) Cultivation of transplanted rice (C) (in season)(THB 153,406/three years) and cultivation of garlic (G) (drought) (THB 115,091/three years), in which the net return was THB $268,497 /$ three years), and 2) cultivation of transplanted glutinous rice (B) (in season) (THB 162,371/3 years) and cultivation of Japanese rice (J) (drought) (THB 61,990/three years), in which the net return was THB 224,361/three years. When considering the two alternatives, it was apparent that the income in the first alternative was over the average agricultural household income of Chiang Rai province, as the referred income was THB 225,972/three years (Re) (Figure 2 brown straight line) (Office of National Statistics, 2017). However, the second one provided a similar result to the references.

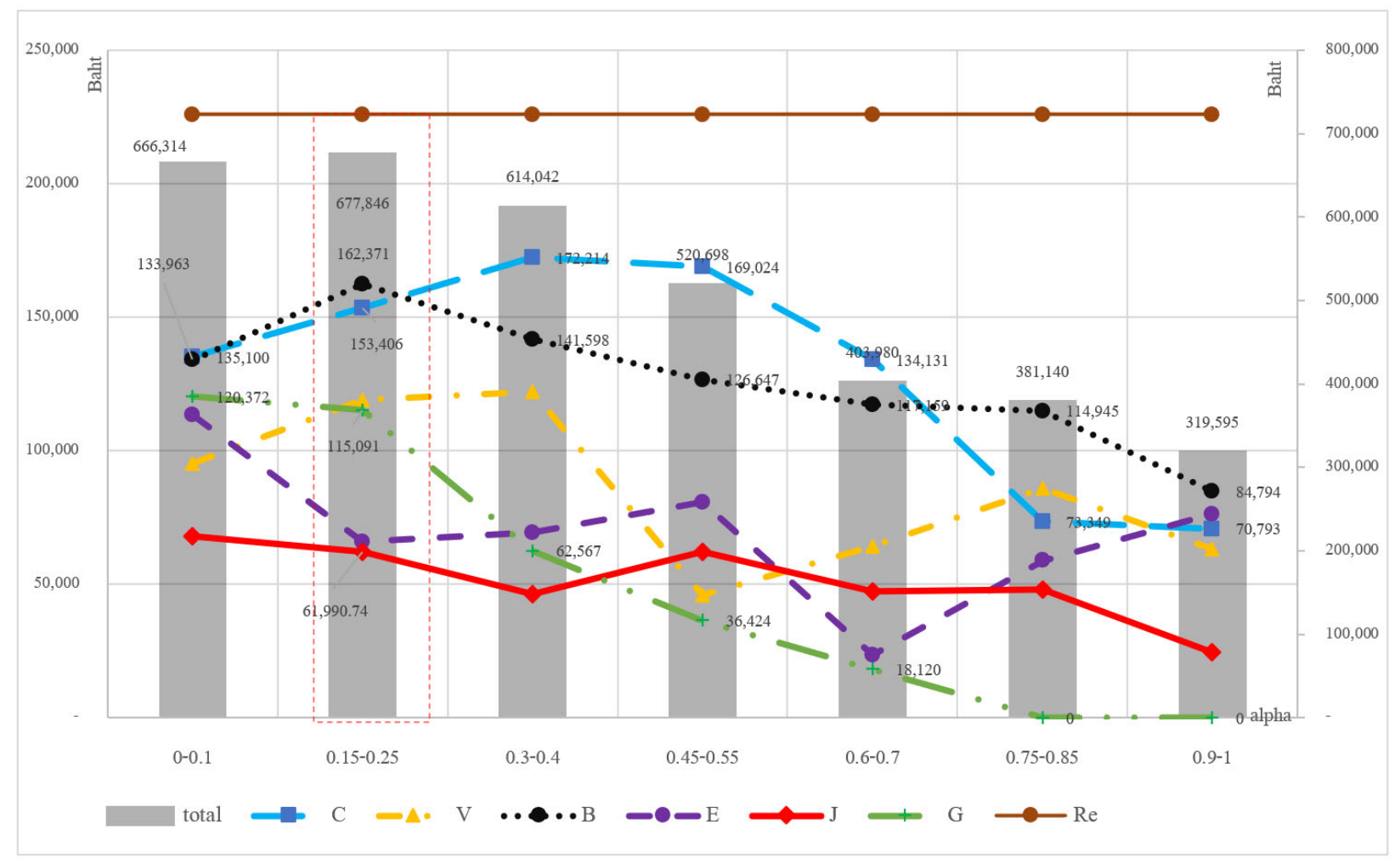

Fig. 2. Total three-year net return at various $\alpha$ prices and yields (at $\lambda=0.15)$.

Trade-off rate between the net profit of every crop: Trade-off at $\alpha=0.15-.25$ (Fig. 2 red dotted frame) indicated the decrease of the return of Japanese rice $(\mathrm{J})$ to THB 1 . On the contrary, the return of garlic $(\mathrm{G})$ increased by THB 1.82 (cultivation in drought), so the returns of transplanted rice (C) and transplanted glutinous rice (B) increased by THB 2.48 and THB 2.51, respectively. Moreover, comparing the trade-off between sown rice and the transplanted cultivations, it was found that the return of transplanted glutinous rice (E) decreased by THB 1, thus resulting in the return of sown paddy rice (V) increasing by THB 1 and the return of transplanted rice $(C)$ increasing by THB 1.29.

The model of resource utilization and the current resource utilization: This section was divided into two models: Model 1 was the uncertain product price and the selection between efficiency and equity, whereas Model 2 was the selection of the answer $(\lambda=0.15)$ that resulted in a maximum net return under the certainty of the price and product $(\alpha=0.15-.25)$. The results of the models showed that less than 4,358 rai of land was used, which was the total size of the study. This could provide a net return similar to or more than the average return amounting to THB 225,972. Table 3 demonstrates Model 1 as the optimism $(\alpha=0)$, and the equity was set at a high level or $\lambda=1-0.01$ that affected the maximum net return average at THB 270,000 , followed by THB 257,000. The in season cultivation included transplanted glutinous rice (B) or transplanted rice 
(C), while the cultivation during the drought included garlic $(\mathrm{G})$. When reducing the product price (pessimistic) $(\alpha=0.5)$ and increasing the efficiency (reducing equity) $\lambda=0.3-0.4$, the net return average would be THB 224,634 as transplanted rice (C) and garlic $(\mathrm{G})$ were still the appropriate alternatives. For Model 2, when setting an uncertain price $\left(\widetilde{P_{i t}}\right)$ and yield $\left(\widetilde{y_{i t}}\right)$, the relationship turned over at $(\alpha=0.15-.25)$. Transplanted rice and transplanted glutinous rice were still the best options, while Japanese rice $(J)$ was another alternative for cultivation during drought because the net return with cultivating transplanted rice (B) reached THB 224,361. As for the demand of the area and employed labor, the value in Model 1 increased, especially when the product price decreased (pessimistic) ( $\alpha$ increasing). The increase of the product quantity was required to redeem the reduction of the price. In consequence, the area $\left(A r e a_{i t j}\right)$ and employed labor $\left(H i L a_{i t j}\right)$ was increased as seen in Model

1. The use of the area increased to 3,092 rai, 3,560 rai, and 4,240 rai, respectively, while the demand for employment also rose; to be precise, from 1,560 persons/month to 1,643 persons/month, and 2,851 persons/month, respectively. When calculating the value of using employed labor (wage amounting to THB 350/person/day and hiring for 25 days), this totaled THB 13.4 million/month, THB 31.1 million/month, and THB 37.1 million/month, respectively (Table 3). The supply of local household labor was approximately 1,701 persons/month. Therefore, this probably caused an agricultural labor shortage when the cultivation area expanded $(\alpha>0.5)$.

Table 3

The use of the inputs, resources, and return from the model compared with the current situation.

\begin{tabular}{|c|c|c|c|c|c|}
\hline & $\begin{array}{l}\text { Current } \\
\text { Situation }\end{array}$ & $\begin{array}{c}\alpha=0 \\
\lambda=0-01\end{array}$ & $\begin{array}{c}\alpha=05 \\
\lambda=03-04\end{array}$ & $\begin{array}{c}\alpha=1 \\
\lambda=0.9-1\end{array}$ & $\begin{array}{c}\alpha=015-025 \\
\lambda=015\end{array}$ \\
\hline $\begin{array}{l}\text { 1. Total area for growing rice with high and } \\
\text { moderate suitability. }\end{array}$ & 4,358 & $377-3,092$ & $93-3,560$ & $86-4,240$ & $86-4,240$ \\
\hline $\begin{array}{l}\text { 1.1 Total area of the agriculturists who joined } \\
\text { the large rice plots (rai). }\end{array}$ & 858 & $38-858$ & $14-838$ & $7-788$ & $14-858$ \\
\hline $\begin{array}{l}1.2 \text { Total area of the agriculturists who had the } \\
\text { potential to join the large rice plots in the future } \\
\text { (rai). }\end{array}$ & 3,500 & $15-2,313$ & $15-3,500$ & $10-3,500$ & $14-3,479$ \\
\hline $\begin{array}{l}\text { 2. Water requirement for cultivation (million } \\
\text { cubic meters/month). }\end{array}$ & - & $0.06-0.63$ & $0.04-0.63$ & $0.1-0.63$ & $0.63-1.27$ \\
\hline 3. Amount of household labor (person/month) & 1,701 & & & & \\
\hline 4. Demand for hire labor (person/month) & & $40-1,540$ & $25-1,643$ & $48-2,851$ & $28-1,415$ \\
\hline $\begin{array}{l}\text { 5. Average return of the agriculturist household } \\
\text { (Baht/three years) } \\
\text { 5.1 Transplanted rice (C) (in season) and } \\
\text { garlic (G) (off season). } \\
\text { 5.2 Transplanted glutinous rice (B) (in } \\
\text { season) and garlic (G) (off season). } \\
\text { 5.3 Transplanted glutinous rice (B) (in } \\
\text { season) and Japanese rice (J) (off season). }\end{array}$ & & $\begin{array}{c}257,0 \emptyset 0 \\
\vdots \\
270,090 \\
\vdots \\
\vdots\end{array}$ & $\begin{array}{c}224,634 \\
\vdots \\
157,328\end{array}$ & 178,385 & 268,97979 \\
\hline
\end{tabular}

Source: From the field survey and calculated.

\section{Discussion and Conclusions}

The agriculturists showed interest in cooperating to follow the large agricultural plot guidelines, but still had ambiguity toward the practices. As a result, the use of MCDM was regarded as a major tool for supporting their decision. The results of the study represented that the agriculturalists mainly gave priority to the economic factors, particularly the price factors because the living costs and production costs were higher, and this prioritized the economic factors before health and the environment. The results from the model demonstrated that transplanted rice or a system of rice intensification could provide a higher and more sustainable return to the large agricultural plot guidelines. The crop transplantation conformed to the study of Cheamuangphan et al. (2019), as the transplanted rice product was higher than the sown rice; this affected the uncertainty of the low price. Apart from this, trade-offs affected the opportunity cost (Beck et al., 2008) of the return from the cultivation of the six alternative crops. It was found that transplanted glutinous rice had the highest opportunity cost, and transplanted rice was the second highest. In addition, the use of production factors from the model demonstrated the allocation in accordance with the Pareto optimality, as the use of the production factor (area and labor) was reduced in Models 1 and 2. Simultaneously, the return increased, which reflected the enhancement of efficient resource utilization, which conformed to the study of Biswas and Pal (2005) and Panyasit, et al. (2021). The large agricultural plot policy aimed at reducing the production costs and enhancing the competitiveness for agriculturists. Therefore, the use of MCDM would support the agriculturist's decisionmaking toward cultivation in the large agricultural plot system, which was regarded as major guidelines to achieve the aforementioned goal sustainably. Because most agriculturists shared a mutual agreement to participate in building the mathematic model, the results demonstrated the uncertainty of the product price resulting in the use of the production resources (land and labor), which increased as a means to redeem the decreased return. Because of the current situation that most agriculturalists were aged not over 55 years, this resulted in the highest risk of the labor shortage. Therefore, the development 
of transplanted rice technology to reduce labor would be very important for the promotion of rice production in the future. Additionally, the uncertainty effect in the economy (low product price) and nature (drought) would lead to production that would focus on efficiency. To be precise, the agriculturalists would produce fewer crops (paddy rice and Japanese rice) and would cultivate fewer local plants (glutinous rice and garlic) until there was a consumption demand outside the community, which would definitely decrease the production capacity and affect the food instability. In consequence, the decision-maker would need to retain the criteria by carefully selecting the right combination between efficiency (produce fewer crop types) and equity (produce various crop types). Nowadays, 67 households of agriculturalists in the area of Phan district, Chiang Rai province have gathered to practice the large agricultural plot system, and there are potential farmers that could join the group, who have more than 3,500 rai (totaling 4,358 rai). The results from the model demonstrated the land used less than 4,358 rai, but could receive a net return similar to or more than THB 225,972 in three years. In consequence, the policy recommendation for the area expansion of the large agricultural plot group would reduce the return risk from the uncertain price and low output (drought) if selecting these alternatives: 1) Transplanted rice (C) (in season) and garlic (G) (drought), 2) transplanted glutinous rice (B) (in season and garlic $(\mathrm{G})$ (drought), and 3) transplanted glutinous rice (B) (in season) and Japanese rice (J) (drought).

\section{Acknowledgement}

This work has supported by The Optimal Decision Making for Using Input Factors to Enhance the Farmers Competitiveness in the Upper Northern Region under the Large Agricultural Land Plot and Research and Graduate Studies, Khon Kaen University, Thailand.

\section{References}

Ayoub, N., Elmoshi, E., Seki, H., \& Naka, Y. (2009). Evolutionary algorithms approach for Integrated bioenergy supply chains optimization. Energy Conversion and Management, 50(12), 2944-2955.

Beck, J., Kempener, R., Cohen, B., \& Petrie, J. (2008). A complex systems approach to planning, optimization and decision making for energy networks. Energy Policy, 36(8), 2795-2805.

Biswas, A., \& Pal, B. B. (2005). Application of fuzzy goal programming technique to land use planning in agricultural system. Omega-International Journal of Management Science, 33(5), 391-398.

Callesen, I., Grohnheit, P. E., \& Ostergard, H. (2010). Optimization of bioenergy yield from cultivated land in Denmark. Biomass \& Bioenergy, 34(9), 1348-1362.

Celik, M., Kandakoglu, A., \& Er, D. (2009). Structuring fuzzy integrated multi-stages evaluation model on academic personnel recruitment in MET institutions. Expert Systems with Applications, 36, 6918-6927 decision-making methods for bioenergy systems. Energy, 25, 1-11.

Cheamuangphan, A., Singhavara, M., \& Paoumnuaywit, A. 2019. The efficiency of large agricultural plot production of farmers in the Upper Northern Region. Completed Report, The Office of Agricultural Research and Extension Maejo University. [In Thai]

Chiang Rai Department of Internal Trade (2019). Main agricultural price of the province. Retrieved from http://www.dit.go.th/ChiangRai/content.asp?deptid=24\&catid=10806.

Chiang Rai Office of Labour (2013). Provincial Labour Statistics. Retrieved from http://chiangrai.mol.go.th/labour_statistic.

Cristobal, J. R. S. (2012). A goal programming model for the optimal mix and location of renewable energy plants in the north of Spain. Renewable \& Sustainable Energy Reviews, 16(7), 4461- 4464.

Department of Irrigation (2014). 40 Crop coefficients (KC). Retrieved from http://water.rid.go.th/hwm/cropwater/iwmd/index_th.htm.

Department of Land Development. (2007). Land use area in Mae Tuen Subdistrict, Li District, Lamphun. (CD-ROM). Abstract: Database of the Department of Land Development.

Jablonski, S., Strachan, N., Brand, C., \& Bauen, A. (2010). The role of bioenergy in the UK's energy future formulation and modelling of long-term UK bioenergy scenarios. Energy Policy, 38(10), 5799-5816.

Panyasit, K., Singhavara, M., Cheamuangphan, A. \& Nonthapot, S. (2021).Decision Planning in Agricultural Production to Achieve a Green Economy in Mae Faek Sub-District, Chiang Mai Province, Thailand. Turkish Journal of Computer and Mathematics Education, 12(6), 2282-2289.

Saaty, T.L. (1980), The Analytic Hierarchy Process, McGraw-Hill, New York, USA. 


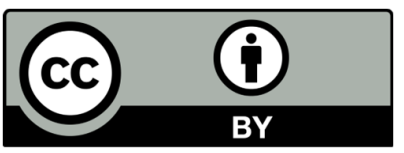

(C) 2022 by the authors; licensee Growing Science, Canada. This is an open access article distributed under the terms and conditions of the Creative Commons Attribution (CCBY) license (http://creativecommons.org/licenses/by/4.0/). 